\title{
Letter to editor: Clinically relevant drug-drug interactions among elderly people with dementia
}

\author{
Carmen Aranda-Salazar ${ }^{1}$ (D) $\cdot$ Jean Mendoza-Ramos ${ }^{1} \cdot$ Alonso Soto $^{1,2}$
}

Received: 19 February 2019 / Accepted: 9 April 2019 / Published online: 29 April 2019

(C) Springer-Verlag GmbH Germany, part of Springer Nature 2019

To the editor,

We have read with interest the article "Clinically relevant drug-drug interactions between elderly people with dementia" [1] published by Sönnerstam E et al. The study reveals important results regarding the prevalence and characteristics of pharmacological interactions and their associated factors in elderly patients with the diagnosis of dementia or cognitive impairment.

Of note, $43.2 \%$ of the population studied had at least one clinically relevant pharmacological interaction. This is important when carrying out the statistical analysis because the odds ratio as a measure of association tends to overestimate the magnitude of the effect in case of high prevalences $[2,3]$ such as the one found. In these cases, it is preferable to use the prevalence ratio (PR) as a measure of association which can be calculated in most statistical packages and can even be obtained from multivariate analysis with statistical routines such as Poisson regression with robust variance [4]. As example, the OR found for the number of medications upon admission was 1.31 , which would correspond to a PR of 1.16 , showing clearly the overestimation of the effect magnitude.
The use of the prevalence ratio would provide an estimate with greater interpretability from the clinical point of view, so it should be used routinely to evaluate the association between dependent and independent variables in cross-sectional studies in which outcomes are frequent as in this study.

\section{References}

1. Sönnerstam E, Sjölander M, Lövheim H (2018) Clinically relevant drug-drug interactions among elderly people with dementia. Eur J Clin Pharmacol 74:1351-1360

2. Tamhane A, Westfall A, Burkholder G, Cutter G Prevalence odds ratio versus prevalence ratio: choice comes with consequences. Stat Med 35(30):5730-5735

3. Schiaffino A, Rodríguez M,Pasarín M, Regidor E, Borrell C, Fernández E (2003) Odds ratio or prevalence ratio? Their use in cross-sectional studies. 17(1):70-74

4. Spiegelman D, Hertzmark E (2005) Easy SAS calculations for risk or prevalence ratios and differences. 162(3):199-200

Publisher's note Springer Nature remains neutral with regard to jurisdictional claims in published maps and institutional affiliations.

Carmen Aranda-Salazar

u201212135@upc.edu.pe

1 Escuela de Medicina, Universidad Peruana de Ciencias Aplicadas (UPC), Prolongación Primavera 2390, 15023 Lima, Peru

2 Departamento de Medicina, Hospital Nacional Hipólito Unanue, El Agustino, Peru 